\title{
Treatment for Osteoporosis among Women in Japan: Associations with Patient Characteristics and Patient-Reported Outcomes in the 2008-2011 Japan National Health and Wellness Surveys
}

\author{
Masayo Sato, ${ }^{1}$ Jeffrey Vietri, ${ }^{2}$ Jennifer A. Flynn, ${ }^{1}$ and Saeko Fujiwara ${ }^{3}$ \\ ${ }^{1}$ Eli Lilly K.K., Lilly Research Laboratories, Kobe 651-0086, Japan \\ ${ }^{2}$ Kantar Health, Health Outcomes Practice, Via Paleocapa 7, 20121 Milan, Italy \\ ${ }^{3}$ Hiroshima Atomic Bomb Casualty Council, Hiroshima 730-0052, Japan \\ Correspondence should be addressed to Jeffrey Vietri; jeffrey.vietri@kantarhealth.com
}

Received 5 August 2014; Revised 26 November 2014; Accepted 27 November 2014; Published 23 December 2014

Academic Editor: Jun Iwamoto

Copyright (c) 2014 Masayo Sato et al. This is an open access article distributed under the Creative Commons Attribution License, which permits unrestricted use, distribution, and reproduction in any medium, provided the original work is properly cited.

\begin{abstract}
This study was conducted to identify characteristics associated with treatment for osteoporosis among women aged 50 years and older in Japan and to explore differences among patients according to treatment regimen. Data were provided by a large annual survey representative of Japanese aged 18 and older; all measures were by self-report. Women aged 50 and older who reported diagnosed osteoporosis $(N=900)$ were compared based on current treatment status using bivariate statistics and logistic regression. Approximately 1 in 3 women in this study reporting diagnosed osteoporosis were currently untreated. Factors associated with current treatment for osteoporosis included having $\geq 1$ physician visit in the prior 6 months $(\mathrm{OR}=5.4, P<0.001)$, self-rated moderate or severe osteoporosis $(\mathrm{OR}=2.8, P<0.001)$, completion of menopause $(\mathrm{OR}=1.6, P<0.05)$, and family history of osteoporosis $(\mathrm{OR}=1.5, P<0.05)$, while longer duration of osteoporosis diagnosis $(\mathrm{OR}=0.9, P<0.05)$ and arthritis $(\mathrm{OR}=0.7$, $P<0.05)$ were associated with lower odds of treatment. These findings suggest that diagnosed patients are not being actively managed in the longer term, and efforts need to be made to ensure that patients stay engaged with their healthcare providers.
\end{abstract}

\section{Introduction}

Osteoporosis is characterized by low bone mass density (BMD) and increased likelihood of bone fracture [1]. Fracture sequelae include pain, stature changes, decreased independence, psychiatric distress, increased hospitalization, and increased morbidity and mortality [2,3]. Population-based estimates indicate that greater than 15 million people are affected by osteoporosis in Japan, with billions (\$US) spent in Japan for hospital care of fractures [4].

Epidemiological estimates of the annual incidence of osteoporosis in Japan are $0.6 \%$ for men and $2.3 \%$ for women aged 40-79 [1]. Fracture rates indicate the burden of the disease on society, with hip fracture incidence increasing 1.7fold from 1987 to 1997. With incidence of osteoporotic hip fractures in Japan estimated at approximately 31,300 men and
116,800 women per year [5], the 10-year probability of hip fracture is greater in Japan than in China or Korea [6-8].

The reduction of BMD with age and after menopause makes women older than 50 years a particularly vulnerable group. Residual lifetime risk of hip fracture in those 50 years of age in the Tottori prefecture, Japan, was recently estimated at $5.6 \%$ for men but $20.0 \%$ for women [6]. Vertebral fracture risk is also high in Japanese women, at 59.7 per 1,000 personyears for women aged 60-69 and 141 per 1,000 person-years in women aged more than 80 years [9]. Incidence of multiple vertebral fractures (i.e., vertebral fracture cascades) is higher in 65-75-year-old Japanese women than same-age nonnative Japanese women or Caucasian women [10, 11]. Moreover, vertebral fracture cascades confer particularly poor health outcomes (e.g., chronic pain, kyphosis, difficulties in performing daily activities, and death) relative to single vertebral 
fractures or other fractures [12]. The problem is likely to worsen in the future, as an increase is expected in the number of people older than 50 years old as the population ages, as well as a continued shift of population from rural areas where exposure to sunlight facilitates production of endogenous vitamin D to urban areas with less sun exposure [4].

However, pharmacotherapy is efficacious in slowing or halting bone loss, maintaining skeletal health, and reducing fracture risk. Common therapies include bisphosphonates and selective estrogen receptor moderators (SERMs), such as raloxifene, and calcitonin. These antiresorptive drugs reduce bone turnover by inhibiting osteoclastic activity, thus improving BMD and bone microarchitecture [13]. Active vitamin $\mathrm{D}_{3}$ is also frequently prescribed. A recent population-based study in Japan estimated the prevalence of vitamin D insufficiency at $81.3 \%$ and deficiency at $1.2 \%$ [14]. In the elderly, low vitamin $\mathrm{D}$ increases risk for falls which precipitate fracture. Due to these high insufficiency/deficiency rates, treatment guidelines indicate active vitamin $\mathrm{D}_{3}$ pharmacotherapies, which are more commonly used in Japan than elsewhere $[1,13]$.

Algorithms can be used to help determine osteoporotic fracture risk and therefore whether to initiate pharmacotherapy (e.g., Fracture Risk Assessment Tool, FRAX). Variables generally considered in such algorithms include age, gender, $\mathrm{BMD}$, experience of previous fracture, site of previous fracture, family history of osteoporosis, body mass index (BMI), use of glucocorticoid medication, alcohol use, and tobacco use $[1,15,16]$. The relationship between experience of a previous fracture and risk for future fractures is strong but the follow-up and treatment of those who have experienced osteoporotic fractures are often considered inadequate. Improving secondary-fracture prevention is thus a current focus of a campaign by the International Osteoporosis Foundation ("Capture the Fracture" [4, 17]).

Despite availability of efficacious pharmacotherapy, a low proportion of those suffering osteoporotic fractures in Japan-as elsewhere-are actually treated prior to fracture, and some who experience an osteoporotic fracture do not receive follow-up treatment for osteoporosis $[15,18,19]$. Identifying relationships between patient characteristics and osteoporosis treatment status may help to elucidate which patients are more or less likely to receive treatment, and whether factors generally considered when evaluating fracture risk are also associated with receiving treatment. Awareness of factors associated with undertreatment may allow for better targeting of efforts to increase treatment uptake. Another gap in our knowledge regards data on patientreported health outcomes according to type of treatment. Little is known, for example, on whether there is a relationship between the type of osteoporosis pharmacotherapy received and health outcomes in real-world patients in Japan.

With this background, the primary study objective was to identify health-related and sociodemographic personal characteristics associated with current osteoporosis treatment among Japanese women (50 years and older) diagnosed with osteoporosis. A secondary, exploratory objective was to describe patient-reported outcomes according to type of pharmacotherapy to generate hypotheses for future research.

\section{Methods}

The current study used data from the $2008(N=20,000)$, $2009(N=20,573), 2010(n=25,000)$, and $2011(N=30,000)$ Japan National Health and Wellness Surveys (NHWS; Kantar Health, New York, NY), an annual, cross-sectional study of individuals aged 18 years or older in Japan. The NHWS includes information related to diagnosis and treatment of a broad variety of conditions, health-related attitudes, health risk behaviors, and health-related outcome measures. Potential respondents to the NHWS are recruited through an existing web-based consumer panel, which recruits its members through opt-in emails, coregistration with panel partners, enewsletter campaigns, banner placements, and both internal and external affiliate networks. All panelists explicitly agreed to be a panel member, registered with the panel through a unique email address, and completed an in-depth demographic registration profile.

The sample for NHWS is selected from this panel using a stratified random sample framework with quotas based on gender and age. Previous research has found the demographic composition of the Japan NHWS to be comparable to that of the Japanese adult population on important parameters [20]. Because sampling for NHWS is without regard to previous participation, a given respondent may have participated in more than one survey during the four-year period reviewed here. Only the most recent data for such individuals were included so as to avoid nonunique responses. All respondents to NHWS provided informed consent, and each of the annual surveys was approved by Essex Institutional Review Board (Lebanon, NJ). Because of the focus on treatment within diagnosed osteoporosis, only women aged 50 and older who reported a physician diagnosis of osteoporosis were included in the present study.

All information was collected through self-report. Variables collected in the NHWS which were of interest for the comparison between treated and untreated patients included sociodemographic and health characteristics, patient characteristics specific to osteoporosis, fracture risk factors, and healthcare resource use. Sociodemographic characteristics included age, household income, marital status, and level of education. General health characteristics included body mass index, use of alcohol, cigarettes, exercise, use of oral glucocorticoid medications, and comorbidity burden according to the Charlson comorbidity index (CCI) [21]. Factors specific to osteoporosis included self-rated severity of osteoporosis, length of diagnosis, and whether the respondent had received a BMD scan. Known risk factors for fracture not already mentioned above included previous fracture since age 50, family history of osteoporosis, back pain, and arthritis. Healthcare resource use variables included whether the individual visited a physician in the prior six months, whether she made a visit to the emergency room in the prior 6 months, and whether she was admitted to the hospital in that time.

The exploratory comparison of outcomes included scores from the revised Medical Outcomes Study 12-Item Short Form Survey Instrument (SF-12v2), a multipurpose, generic instrument comprised of 12 questions [22]. This instrument can be used to summarize functional health by two summary 
scores, the physical component summary (PCS) and mental component summary (MCS). Each score has a mean of 50 and a standard deviation of 10 for the Japanese population [23], with higher scores indicating better health. Several of the items from the SF-12v2 can be used to generate a health state utility score, the SF-6D. The SF-6D is a preferencebased single index measure for health using general population values [24]. The SF-6D index has interval scoring properties and yields summary scores on a theoretical 0-1 scale (with an empirical floor of 0.3). Higher scores indicate better quality of life. Ratings of impairment in nonwork activities (activity impairment) from the Work Productivity and Activity Impairment questionnaire were also included. This measure yields a percentage from 0 to $100 \%$ with higher ratings indicating more health-related impairment [25]. The numbers of physician visits, emergency room (ER) visits, and hospitalizations in the prior 6 months were also collected from the survey.

2.1. Analysis. The primary objective of identifying patient characteristics associated with current treatment was addressed by comparing women currently being treated for osteoporosis with those not currently treated, using chisquare for categorical variables and $t$-test for continuous variables. This was followed by binary logistic regression to assess which patient characteristics were associated with higher adjusted odds of current use of prescription treatment for osteoporosis when considered simultaneously.

To explore differences in outcomes according to type of treatment, the group currently receiving treatment for osteoporosis was further subdivided according to the primary type of medication used. Four groups were constructed to allow for inclusion of common treatment patterns while excluding more complicated combinations of medications that would have smaller sample sizes and reflected the treatment patterns observed in the sample rather than official recommendations (i.e., [1]). The groups were raloxifene (the only SERM used by respondents in this sample) without a bisphosphonate, bisphosphonate (alendronate, minodronic acid, risedronate, or zoledronic acid) without raloxifene, active vitamin $\mathrm{D}_{3}$ (alfacalcidol, calcitriol) without other osteoporosis medication, and calcitonin without other osteoporosis medications. Respondents in the raloxifene and bisphosphonate categories were still included in these categories if using active vitamin $\mathrm{D}_{3}$, as prescribing these medications in combination with another osteoporosis medication is common practice in Japan. Patient characteristics and outcomes were compared using one-way ANOVA for continuous variables and chisquare for categorical variables. The outcomes of the treatment groups were also compared using generalized linear models incorporating treatment group along with age, household income, BMI category, length of diagnosis, and CCI. Models of health-related quality of life incorporated a normal probability distribution and identity function. Models of activity impairment and healthcare use specified a negative binomial distribution and a log-link function. A 5\% (twotailed) alpha error rate was adopted for all null-hypothesis tests; no adjustments were made for multiplicity.

\section{Results}

Response rates for the NHWS Japan surveys providing data for this study were $40.0 \%, 22.7 \%, 24.9 \%$, and $15 \%$ in 2008 through 2011, respectively. A total of 17,722 unique women aged 50 and older were identified, and 900 (5\%) reported physician diagnosis of osteoporosis. These respondents with osteoporosis were approximately 67 years old on average (range 50 to 92) and had been diagnosed for a mean of 5.3 years. The majority $(65.1 \%)$ of respondents diagnosed with osteoporosis were currently being treated with a prescription medication. Most reported completing menopause $(75.4 \%)$ and having previously had a BMD scan (89.4\%). Fewer than half reported a fracture since age 50 (37.3\%), and a similar number reported their osteoporosis was moderate or severe (41.2\%) as opposed to mild.

Unadjusted comparisons showed a variety of differences in the characteristics of patients by treatment status (Table 1). Those who were currently treated were slightly older on average, more likely to have completed menopause, more likely to report moderate or severe osteoporosis, and more likely to have visited a physician in the prior 6 months. There were also trends that approached significance $(P<$ 0.10 ), with those currently treated for osteoporosis potentially having a greater likelihood of reporting daily alcohol use, reporting vigorous exercise in the previous month, to currently use glucocorticoid medication, to have a family history of osteoporosis, and to report a fracture since age 50 relative to those diagnosed but not currently treated.

Twenty-three respondents were excluded from the regression due to missing data for length of diagnosis. The multivariable logistic regression revealed that several personal and disease characteristics were associated with greater odds of current treatment (Table 2), though the pattern of significant variables differed somewhat from the bivariate analysis. Factors significantly associated with current treatment included having completed menopause, having a family history of osteoporosis, reporting moderate or severe osteoporosis (relative to mild), and having visited a physician in the prior 6 months. Lower adjusted odds of treatment were associated with arthritis and longer duration of diagnosis. There was also a trend for those who were not sure of having a BMD scan to be less likely to be treated relative to those who did have a $\operatorname{scan}(P=0.052)$. No other variables approached significance in this regression (all $P>0.10$ ).

The category definitions were chosen for the exploratory comparison of treatments provided for inclusion of $77 \%$ (450/586) of respondents currently using osteoporosis medications in the sample and $50 \%$ of the total sample reporting a physician diagnosis of osteoporosis. Patient characteristics according to type of treatment are presented in Table 3 . There were no significant differences between the groups, though there was a trend $(P=0.065)$ for cigarette smoking to differ across treatment groups, with raloxifene users having a very high proportion of respondents who indicated that they never have smoked cigarettes.

Bivariate comparison of unadjusted outcomes by type of treatment is presented in Table 4. Only differences in mean MCS scores across the groups approached statistical 
TABLE 1: Characteristics of women in Japan diagnosed with osteoporosis.

\begin{tabular}{|c|c|c|c|c|c|c|c|}
\hline & \multicolumn{6}{|c|}{ Osteoporosis treatment status } & \\
\hline & \multicolumn{2}{|c|}{ Total $(N=900)$} & \multicolumn{2}{|c|}{ Currently treated $(N=586)$} & \multicolumn{3}{|c|}{ Not currently treated $(N=314)$} \\
\hline & Mean & SD & Mean & $\mathrm{SD}$ & Mean & $\mathrm{SD}$ & $P$ value ${ }^{1}$ \\
\hline Age (years) & 66.9 & 7.45 & 67.3 & 6.9 & 66.2 & 8.3 & 0.033 \\
\hline CCI & 0.30 & 1.54 & 0.34 & 1.87 & 0.23 & 0.55 & 0.285 \\
\hline \multirow[t]{2}{*}{ Length of diagnosis (years) } & 5.3 & 5.5 & 5.1 & 5.5 & 5.7 & 5.6 & 0.127 \\
\hline & $n$ & $\%$ & $n$ & $\%$ & $n$ & $\%$ & $P$ value $^{2}$ \\
\hline Married/living with partner & 627 & $69.7 \%$ & 409 & $69.8 \%$ & 218 & $69.4 \%$ & 0.909 \\
\hline University degree & 150 & $16.7 \%$ & 97 & $16.6 \%$ & 53 & $16.9 \%$ & 0.900 \\
\hline Household income & & & & & & & 0.848 \\
\hline Below median & 472 & $52.4 \%$ & 305 & $52.0 \%$ & 167 & $53.2 \%$ & \\
\hline Above median & 341 & $37.9 \%$ & 222 & $37.9 \%$ & 119 & $37.9 \%$ & \\
\hline Decline to answer income & 87 & $9.7 \%$ & 59 & $10.1 \%$ & 28 & $8.9 \%$ & \\
\hline Cigarette smoking & & & & & & & 0.317 \\
\hline Never & 694 & $77.1 \%$ & 449 & $76.6 \%$ & 245 & $78.0 \%$ & \\
\hline Current & 87 & $9.7 \%$ & 53 & $9.0 \%$ & 34 & $10.8 \%$ & \\
\hline Former & 119 & $13.2 \%$ & 84 & $14.3 \%$ & 35 & $11.1 \%$ & \\
\hline Daily alcohol use & 68 & $7.6 \%$ & 51 & $8.7 \%$ & 17 & $5.4 \%$ & 0.075 \\
\hline Exercise & 504 & $56.0 \%$ & 342 & $58.4 \%$ & 162 & $51.6 \%$ & 0.051 \\
\hline BMI categories & & & & & & & 0.212 \\
\hline Underweight & 115 & $12.8 \%$ & 76 & $13.0 \%$ & 39 & $12.4 \%$ & \\
\hline Normal & 676 & $75.1 \%$ & 446 & $76.1 \%$ & 230 & $73.2 \%$ & \\
\hline Overweight or obese & 90 & $10.0 \%$ & 50 & $8.6 \%$ & 40 & $12.7 \%$ & \\
\hline Declined to answer weight & 19 & $2.1 \%$ & 14 & $2.4 \%$ & 5 & $1.6 \%$ & \\
\hline Completed menopause & 679 & $75.4 \%$ & 463 & $79.0 \%$ & 216 & $68.8 \%$ & 0.001 \\
\hline On glucocorticoids & 41 & $4.6 \%$ & 32 & $5.5 \%$ & 9 & $2.9 \%$ & 0.075 \\
\hline Back pain & 113 & $12.6 \%$ & 78 & $13.3 \%$ & 35 & $11.1 \%$ & 0.350 \\
\hline Arthritis & 160 & $17.8 \%$ & 98 & $16.7 \%$ & 62 & $19.7 \%$ & 0.258 \\
\hline Family history of osteoporosis & 194 & $21.6 \%$ & 137 & $23.4 \%$ & 57 & $18.2 \%$ & 0.069 \\
\hline BMD scan & & & & & & & 0.026 \\
\hline Yes & 805 & $89.4 \%$ & 536 & $91.5 \%$ & 269 & $85.7 \%$ & \\
\hline No & 58 & $6.4 \%$ & 31 & $5.3 \%$ & 27 & $8.6 \%$ & \\
\hline Do not know & 37 & $4.1 \%$ & 19 & $3.2 \%$ & 18 & $5.7 \%$ & \\
\hline Previous fracture since age 50 & 336 & $37.3 \%$ & 232 & $39.6 \%$ & 104 & $33.1 \%$ & 0.056 \\
\hline Moderate or severe osteoporosis & 371 & $41.2 \%$ & 287 & $49.0 \%$ & 84 & $26.8 \%$ & $<0.001$ \\
\hline Visited physician & 829 & $92.1 \%$ & 565 & $96.4 \%$ & 264 & $84.1 \%$ & $<0.001$ \\
\hline Visited ER & 68 & $7.6 \%$ & 43 & $7.3 \%$ & 25 & $8.0 \%$ & 0.736 \\
\hline Hospitalized & 82 & $9.1 \%$ & 57 & $9.7 \%$ & 25 & $8.0 \%$ & 0.380 \\
\hline
\end{tabular}

${ }^{1}$ Independent-samples $t$-test; ${ }^{2}$ Pearson chi-square test; CCI: Charlson comorbidity index; BMD: bone mineral density; BMI: body mass index; ER: emergency room.

significance $(P<0.10)$, with no differences reaching the critical level of $P<0.05$. Generalized linear models of health outcomes excluded 8 respondents due to missing data for duration of diagnosis. After adjustment for age, household income, BMI category, length of diagnosis, and CCI, there was a significant relationship between treatment group and MCS scores $(P<0.05)$. Treatment group was not significant in the models of other outcomes (Table 5).

\section{Discussion}

Study findings showed that approximately one-third of women already diagnosed with osteoporosis in Japan aged 50 and older contacted during four years of data collection were not currently using a prescription. This suggests that many women who would likely benefit from osteoporosis treatment are not receiving it. The factor most strongly related to 
TABLE 2: Adjusted odds ratios of current treatment among women aged 50 and older in Japan with diagnosed osteoporosis $(N=877)$.

\begin{tabular}{|c|c|c|c|c|}
\hline \multirow{2}{*}{ Factor } & \multirow{2}{*}{ OR } & \multicolumn{2}{|c|}{ 95\% confidence interval } & \multirow{2}{*}{$P$ value } \\
\hline & & Low & High & \\
\hline Age (5-year increment) & 1.045 & 0.924 & 1.181 & 0.486 \\
\hline Married/living with partner & 1.080 & 0.763 & 1.529 & 0.665 \\
\hline University degree & 1.015 & 0.665 & 1.550 & 0.945 \\
\hline \multicolumn{5}{|l|}{ Household income } \\
\hline Low income & \multicolumn{4}{|c|}{ Reference } \\
\hline High income & 1.176 & 0.835 & 1.657 & 0.353 \\
\hline Declined to answer income & 1.265 & 0.733 & 2.185 & 0.399 \\
\hline \multicolumn{5}{|l|}{ Cigarette smoking } \\
\hline Never smoker & \multicolumn{4}{|c|}{ Reference } \\
\hline Current smoker & 0.810 & 0.476 & 1.379 & 0.438 \\
\hline Former smoker & 1.321 & 0.827 & 2.110 & 0.244 \\
\hline Daily alcohol use & 1.654 & 0.868 & 3.152 & 0.126 \\
\hline Exercise & 1.048 & 0.761 & 1.443 & 0.774 \\
\hline \multicolumn{5}{|l|}{ BMI category } \\
\hline Underweight & 1.162 & 0.727 & 1.859 & 0.530 \\
\hline Normal weight & \multicolumn{4}{|c|}{ Reference } \\
\hline Overweight or obese & 0.719 & 0.435 & 1.19 & 0.199 \\
\hline Declined to answer weight & 1.852 & 0.585 & 5.864 & 0.295 \\
\hline CCI & 1.028 & 0.87 & 1.214 & 0.747 \\
\hline Completed menopause & 1.587 & 1.084 & 2.323 & 0.018 \\
\hline On oral glucocorticoids & 2.106 & 0.841 & 5.269 & 0.112 \\
\hline Back pain & 1.237 & 0.761 & 2.011 & 0.390 \\
\hline Arthritis & 0.654 & 0.435 & 0.982 & 0.040 \\
\hline Family history of osteoporosis & 1.472 & 1.001 & 2.164 & 0.049 \\
\hline \multicolumn{5}{|l|}{ BMD scan history } \\
\hline Has had BMD scan & \multicolumn{4}{|c|}{ Reference } \\
\hline Never had BMD scan & 0.749 & 0.405 & 1.385 & 0.357 \\
\hline Not sure of BMD scan & 0.473 & 0.222 & 1.007 & 0.052 \\
\hline Previous fracture since age 50 & 1.26 & 0.905 & 1.756 & 0.172 \\
\hline Moderate or severe osteoporosis (relative to mild) & 2.777 & 1.991 & 3.873 & $<0.001$ \\
\hline Duration of osteoporosis (5-year increment) & 0.857 & 0.745 & 0.986 & 0.031 \\
\hline \multicolumn{5}{|l|}{ Healthcare use } \\
\hline Visited physician (past 6 months) & 5.374 & 3.007 & 9.604 & $<0.001$ \\
\hline Visited ER (past 6 months) & 0.842 & 0.456 & 1.555 & 0.583 \\
\hline Hospitalized (past 6 months) & 0.926 & 0.513 & 1.670 & 0.798 \\
\hline
\end{tabular}

CCI: Charlson comorbidity index; BMD: bone mineral density; ER: emergency room.

current treatment among diagnosed women was report of a physician visit in the prior 6 months, suggesting that regular follow-up with healthcare providers may be a key factor in determining whether or not women receive osteoporosis treatment. This finding is consistent with the result for duration of diagnosis; after taking into account other relevant variables, longer duration of diagnosis was associated with lower odds of treatment. This is consistent with previous research on persistence and adherence to osteoporosis medications, which are low both inside and outside Japan [26-30]. Other significant correlates of treatment status corresponded with identified risk factors for fracture, including menopausal status, family history of osteoporosis, and perceptions of more-severe osteoporosis. It is a positive sign that women with these risk factors for fracture are being treated.

However, other fracture risk variables were not associated with treatment status, most notably history of previous fracture. As reported above, the association of previous fracture with an increased risk of future fracture has been widely documented, and secondary fracture prevention is the focus of the IOF's "Capture the Fracture" campaign $[4,17]$. Thus, these results suggest that identifying and treating those with previous fracture may need to be a higher priority for physicians in Japan than it has been in the past. Similarly, age has a strong and clear association with fracture risk [15] but was unrelated to treatment status in this study. However, this may 
TABLE 3: Patient characteristics according to type of osteoporosis treatment $(N=450)$.

\begin{tabular}{|c|c|c|c|c|c|c|c|c|c|}
\hline & \multicolumn{2}{|c|}{$\begin{array}{l}\text { Raloxifene } \\
(N=46)\end{array}$} & \multicolumn{2}{|c|}{$\begin{array}{l}\text { Bisphosphonates } \\
(N=298)\end{array}$} & \multicolumn{2}{|c|}{$\begin{array}{l}\text { Active vitamin } \mathrm{D}_{3} \text { alone } \\
\qquad(N=60)\end{array}$} & \multicolumn{2}{|c|}{$\begin{array}{l}\text { Calcitonin alone } \\
\qquad(N=46)\end{array}$} & \multirow[b]{2}{*}{$P$ value ${ }^{1}$} \\
\hline & Mean & $\mathrm{SD}$ & Mean & SD & Mean & SD & Mean & $\mathrm{SD}$ & \\
\hline Age & 66.5 & 7.0 & 67.1 & 6.9 & 68.4 & 7.5 & 66.8 & 8.0 & 0.490 \\
\hline CCI & 0.15 & 0.36 & 0.41 & 2.53 & 0.47 & 1.02 & 0.20 & 0.50 & 0.787 \\
\hline \multirow[t]{2}{*}{ Length of diagnosis } & 4.6 & 4.4 & 5.2 & 5.8 & 5.6 & 6.0 & 4.9 & 5.1 & 0.934 \\
\hline & $n$ & $\%$ & $n$ & $\%$ & $n$ & $\%$ & $n$ & $\%$ & $P$ value $^{2}$ \\
\hline Married/living with partner & 37 & $80.4 \%$ & 214 & $71.8 \%$ & 39 & $65.0 \%$ & 33 & $71.7 \%$ & 0.382 \\
\hline University degree or greater & 9 & $19.6 \%$ & 48 & $16.1 \%$ & 9 & $15.0 \%$ & 6 & $13.0 \%$ & 0.854 \\
\hline Household income & & & & & & & & & 0.266 \\
\hline Below median & 22 & $47.8 \%$ & 155 & $52.0 \%$ & 30 & $50.0 \%$ & 27 & $58.7 \%$ & \\
\hline Above median & 14 & $30.4 \%$ & 115 & $38.6 \%$ & 24 & $40.0 \%$ & 14 & $30.4 \%$ & \\
\hline Declined answering & 10 & $21.7 \%$ & 28 & $9.4 \%$ & 6 & $10.0 \%$ & 5 & $10.9 \%$ & \\
\hline Cigarette smoking & & & & & & & & & 0.065 \\
\hline Never smoker & 42 & $91.3 \%$ & 227 & $76.2 \%$ & 46 & $76.7 \%$ & 35 & $76.1 \%$ & \\
\hline Current smoker & 2 & $4.3 \%$ & 34 & $11.4 \%$ & 3 & $5.0 \%$ & 2 & $4.3 \%$ & \\
\hline Former smoker & 2 & $4.3 \%$ & 37 & $12.4 \%$ & 11 & $18.3 \%$ & 9 & $19.6 \%$ & \\
\hline Daily alcohol use & 2 & $4.3 \%$ & 34 & $11.4 \%$ & 3 & $5.0 \%$ & 2 & $4.3 \%$ & 0.130 \\
\hline Exercise & 31 & $67.4 \%$ & 172 & $57.7 \%$ & 32 & $53.3 \%$ & 21 & $45.7 \%$ & 0.185 \\
\hline BMI categories & & & & & & & & & 0.994 \\
\hline Underweight & 6 & $13.0 \%$ & 38 & $12.8 \%$ & 7 & $11.7 \%$ & 6 & $13.0 \%$ & \\
\hline Normal & 34 & $73.9 \%$ & 230 & $77.2 \%$ & 47 & $78.3 \%$ & 36 & $78.3 \%$ & \\
\hline Overweight or obese & 5 & $10.9 \%$ & 23 & $7.7 \%$ & 5 & $8.3 \%$ & 4 & $8.7 \%$ & \\
\hline Declined to answer & 1 & $2.2 \%$ & 7 & $2.3 \%$ & 1 & $1.7 \%$ & 0 & $0.0 \%$ & \\
\hline Completed menopause & 37 & $80.4 \%$ & 233 & $78.2 \%$ & 45 & $75.0 \%$ & 36 & $78.3 \%$ & 0.923 \\
\hline On glucocorticoids & 1 & $2.2 \%$ & 19 & $6.4 \%$ & 3 & $5.0 \%$ & 2 & $4.3 \%$ & 0.671 \\
\hline Back pain & 6 & $13.0 \%$ & 38 & $12.8 \%$ & 9 & $15.0 \%$ & 5 & $10.9 \%$ & 0.938 \\
\hline Arthritis & 6 & $13.0 \%$ & 56 & $18.8 \%$ & 10 & $16.7 \%$ & 10 & $21.7 \%$ & 0.712 \\
\hline Family history of osteoporosis & 11 & $23.9 \%$ & 69 & $23.2 \%$ & 17 & $28.3 \%$ & 13 & $28.3 \%$ & 0.770 \\
\hline Have you ever had a bone massdensity test/scan? & & & & & & & & & 0.720 \\
\hline Yes & 43 & $93.5 \%$ & 273 & $91.6 \%$ & 55 & $91.7 \%$ & 42 & $91.3 \%$ & \\
\hline No & 1 & $2.2 \%$ & 15 & $5.0 \%$ & 3 & $5.0 \%$ & 4 & $8.7 \%$ & \\
\hline Not sure & 2 & $4.3 \%$ & 10 & $3.4 \%$ & 2 & $3.3 \%$ & 0 & $0.0 \%$ & \\
\hline Fracture since age 50 & 12 & $26.1 \%$ & 131 & $44.0 \%$ & 23 & $38.3 \%$ & 20 & $43.5 \%$ & 0.135 \\
\hline Moderate or severe osteoporosis & 23 & $50.0 \%$ & 138 & $46.3 \%$ & 27 & $45.0 \%$ & 24 & $52.2 \%$ & 0.847 \\
\hline Visited physician (prior 6 months) & 45 & $97.8 \%$ & 286 & $96.0 \%$ & 56 & $93.3 \%$ & 45 & $97.8 \%$ & 0.591 \\
\hline Visited ER (prior 6 months) & 3 & $6.5 \%$ & 24 & $8.1 \%$ & 7 & $11.7 \%$ & 4 & $8.7 \%$ & 0.780 \\
\hline Visited hospital (prior 6 months) & 4 & $8.7 \%$ & 28 & $9.4 \%$ & 6 & $10.0 \%$ & 3 & $6.5 \%$ & 0.926 \\
\hline
\end{tabular}

${ }^{1}$ One-way ANOVA; ${ }^{2}$ Pearson chi-square test; CCI: Charlson comorbidity index; BMD: bone mineral density; BMI: body mass index; ER: emergency room.

be an expected finding, as in Japan the intervention thresholds take age into account, allowing for higher risk among older patients before the intervention threshold is reached [15]. Other risk factors which were not significantly related to treatment in the present study were current smoking, alcohol use, and use of oral glucocorticoids. However, while included in pharmacotherapy treatment decision tools, the associations between smoking and alcohol use with fracture risk are of a much smaller magnitude than previous fracture [15]. As very few people were on glucocorticoids, the null finding may be the result of insufficient power. Interestingly, those who reported comorbid arthritis were less likely to be currently treated for osteoporosis. One potential explanation is that such patients may have had higher BMD than respondents without arthritis, thereby affecting patients' and/or physicians' perceptions of the urgency of treatment. Osteoarthritis has been associated with higher BMD, though the relationship between osteoarthritis and osteoporosis is still not well 
TABLE 4: Unadjusted mean outcomes according to type of osteoporosis treatment.

\begin{tabular}{|c|c|c|c|c|c|c|c|c|c|}
\hline & \multicolumn{2}{|c|}{$\begin{array}{l}\text { Raloxifene } \\
(N=46)\end{array}$} & \multicolumn{2}{|c|}{$\begin{array}{l}\text { Bisphosphonates } \\
\qquad(N=298)\end{array}$} & \multicolumn{2}{|c|}{$\begin{array}{l}\text { Active vitamin } \mathrm{D}_{3} \text { alone } \\
\qquad(N=60)\end{array}$} & \multicolumn{2}{|c|}{$\begin{array}{l}\text { Calcitonin alone } \\
\qquad(N=46)\end{array}$} & \multirow[t]{2}{*}{$P$ value $^{1}$} \\
\hline & Mean & $\mathrm{SD}$ & Mean & $\mathrm{SD}$ & Mean & $\mathrm{SD}$ & Mean & SD & \\
\hline \multicolumn{10}{|l|}{ HRQoL (SF-12v2) } \\
\hline MCS & 50.97 & 8.46 & 47.55 & 10.59 & 46.64 & 10.77 & 50.07 & 8.93 & 0.063 \\
\hline PCS & 44.52 & 9.35 & 44.73 & 10.71 & 42.93 & 13.37 & 45.05 & 8.42 & 0.676 \\
\hline Health utility score (SF-6D) & 0.745 & 0.139 & 0.718 & 0.141 & 0.703 & 0.151 & 0.756 & 0.135 & 0.163 \\
\hline Activity impairment (\%) & 28.91 & 27.26 & 32.38 & 29.15 & 34.50 & 29.08 & 31.09 & 28.85 & 0.788 \\
\hline \multicolumn{10}{|l|}{ 6-month healthcare use } \\
\hline Physician visits & 10.59 & 8.48 & 15.41 & 16.76 & 17.20 & 19.16 & 12.57 & 14.47 & 0.130 \\
\hline ER visits & 0.09 & 0.35 & 0.32 & 2.06 & 0.37 & 1.63 & 0.15 & 0.51 & 0.796 \\
\hline Hospitalizations & 2.09 & 11.20 & 1.91 & 9.32 & 2.10 & 8.74 & 3.39 & 18.02 & 0.855 \\
\hline
\end{tabular}

${ }^{1}$ One-way ANOVA; HRQoL: health-related quality of life; MCS: mental component summary; PCS: physical component summary; ER: emergency room.

TABLE 5: Regression-adjusted mean outcomes according to type of osteoporosis treatment.

\begin{tabular}{|c|c|c|c|c|c|c|c|c|c|}
\hline & \multicolumn{2}{|c|}{$\begin{array}{l}\text { Raloxifene } \\
(N=46)\end{array}$} & \multicolumn{2}{|c|}{$\begin{array}{l}\text { Bisphosphonates } \\
\quad(N=291)\end{array}$} & \multicolumn{2}{|c|}{$\begin{array}{l}\text { Active vitamin } \mathrm{D}_{3} \text { alone } \\
\qquad(N=59)\end{array}$} & \multicolumn{2}{|c|}{$\begin{array}{l}\text { Calcitonin alone } \\
\qquad(N=46)\end{array}$} & \multirow[t]{2}{*}{$P$ value $^{1}$} \\
\hline & Adjusted mean & SE & Adjusted mean & SE & Adjusted mean & SE & Adjusted mean & SE & \\
\hline \multicolumn{10}{|l|}{ HRQoL } \\
\hline MCS & 50.5 & 1.6 & 46.8 & 0.9 & 45.3 & 1.5 & 49.2 & 1.6 & 0.027 \\
\hline PCS & 42.1 & 1.6 & 42.4 & 0.9 & 40.8 & 1.5 & 42.6 & 1.7 & 0.747 \\
\hline SF-6D & 0.725 & 0.022 & 0.697 & 0.013 & 0.677 & 0.020 & 0.732 & 0.022 & 0.138 \\
\hline Activity impairment (\%) & 30.7 & 4.4 & 33.7 & 2.8 & 34.7 & 4.9 & 32.6 & 4.8 & 0.911 \\
\hline \multicolumn{10}{|l|}{ 6-month healthcare use } \\
\hline Physician visits & 11.9 & 1.8 & 16.5 & 1.4 & 18.3 & 2.5 & 14.6 & 2.2 & 0.102 \\
\hline ER visits & 0.2 & 0.2 & 0.3 & 0.1 & 0.3 & 0.2 & 0.4 & 0.4 & 0.916 \\
\hline Hospitalizations & 4.2 & 3.6 & 2.0 & 0.8 & 1.2 & 1.1 & 1.7 & 1.4 & 0.700 \\
\hline
\end{tabular}

${ }^{1}$ Wald chi-square for treatment group; HRQoL: health-related quality of life; MCS: mental component summary; PCS: physical component summary; ER: emergency room.

understood [31, 32]. We can only speculate on this point as BMD results were not available for survey respondents.

Outcomes were not statistically different across treatment groups excepting MCS scores in the adjusted comparisons. Nevertheless, if replicated in a larger sample, the numeric differences in the mean values of some outcomes would be considered important (i.e., equal to or greater than the minimally important difference [33]). Likewise, the pattern of means also suggests a relationship between treatment type and physician visits that may be worthwhile to explore in further research. It is also important to bear in mind that the significance level was not adjusted to account for multiple comparisons. Indeed, if the Bonferroni correction were applied to maintain 5\% experiment-wise alpha error across the multivariable comparison of the seven outcomes considered here, the critical value would be 0.0071 , lower than any of the observed $P$ values for treatment type.

The present study should be considered in light of the limitations of the methodology. Clinical information about previous treatment or clinical measures such a BMD scan results was not available and would likely explain additional variance in treatment status. The analysis was correlational and cross-sectional and, as is the case for all correlational analyses, directionality of the associations could not be determined. Some variables, such as perceived severity, could have been effects rather than causes of treatment. We were unable to examine composite fracture risk for individual patients, which would have potentially been more valuable than individual risk factors. Survey questions did not allow us to distinguish between undertreatment, problems with treatment initiation, and lack of persistence, which have all been shown to be significant problems in osteoporosis treatment in other populations [26-30].

Response rates to the survey were modest to low, which may have introduced some self-selection bias. It is possible that individuals more invested in, or highly conscious of, their health would be more likely to respond to the study survey. It is not fully clear how such a bias might affect the results. However, the most likely effect would be overestimation of the proportion of women currently treated relative to the actual situation in Japan, as this is a point estimate which would be sensitive to potential differences between the 
responders and nonresponders. It is less clear how the low response rate may have affected the relationships between patient characteristics and treatment status or the exploratory analysis comparing types of treatments. These comparisons were within the same sample (i.e., all were responders to the survey), and so comparison groups would share the same bias rather than having the bias confounded with analysis groups.

As with any self-report survey, measurement error could have been introduced by recall biases or errors. The sample sizes for the exploratory comparison of outcomes by type of treatment were limited, which may have prevented the detection of differences in the treatment groups that could be detected in a larger sample. Finally, the limitation of crosssectional analysis is also applicable to the comparisons of outcomes, and the difference in MCS scores may be a consequence of treatment choice, a cause of treatment choice, or a spurious finding. As previously noted, the exploratory nature of the analysis included numerous hypothesis tests without adjustment for type 1 error.

In summary, approximately one in three women included in this study was not currently being treated with a prescription medication for osteoporosis despite an average length of diagnosis of nearly 6 years. Treatment status was associated with some, but not all, established fracture risk factors. The patient characteristics most strongly associated with current treatment according to the adjusted odds ratios were a recent physician visit and a perception of more-severe osteoporosis, both of which suggest that concern about the disease and contact with a healthcare provider facilitate treatment, while objective risk factors such as age and fracture history were not strongly associated with current treatment. These findings suggest that diagnosed patients are not being actively managed in the longer term, and efforts need to be made to ensure that patients stay engaged with their healthcare providers.

\section{Conflict of Interests}

This research was conducted by Kantar Health with funding from Eli Lilly K.K. Masayo Sato and Jennifer A. Flynn are employees of Eli Lilly K.K., and Jeffrey Vietri is an employee of Kantar Health. Saeko Fujiwara has served on speakers' bureaus for Pfizer, Chugai, Daiichi Sankyo, and Ono Pharmaceutical Company.

\section{Authors' Contribution}

Masayo Sato conceived the study. Jeffrey Vietri conducted the statistical analysis and drafted the paper. Jennifer A. Flynn and Saeko Fujiwara reviewed the paper and revised it for important intellectual content. All authors participated in interpreting the results and approved the final version of the paper for submission.

\section{Acknowledgments}

The authors would like to acknowledge Tammy Schuler for her editorial assistance and Peita Graham-Clarke at Eli Lilly Australia for her helpful comments on this paper.

\section{References}

[1] H. Orimo, T. Nakamura, T. Hosoi et al., "Japanese 2011 guidelines for prevention and treatment of osteoporosis-executive summary," Archives of Osteoporosis, vol. 7, no. 1-2, pp. 3-20, 2012.

[2] T. W. O’Neill and D. K. Roy, "How many people develop fractures with what outcome?" Best Practice and Research: Clinical Rheumatology, vol. 19, no. 6, pp. 879-895, 2005.

[3] M. Shiraki, T. Kuroda, and S. Tanaka, "Established osteoporosis associated with high mortality after adjustment for age and co-mobidities in postmenopausal Japanese women," Internal Medicine, vol. 50, no. 5, pp. 397-404, 2011.

[4] International Osteoporosis Foundation, The Asia-Pacific Regional Audit, 2013, http://www.iofbonehealth.org/sites/default/ files/media/PDFs/Regional\%20Audits/2013-Asia_Pacific_Audit_ 0_0.pdf.

[5] H. Hagino, K. Furukawa, S. Fujiwara et al., "Recent trends in the incidence and lifetime risk of hip fracture in Tottori, Japan," Osteoporosis International, vol. 20, no. 4, pp. 543-548, 2009.

[6] H. Orimo, T. Hashimoto, K. Sakata, N. Yoshimura, T. Suzuki, and T. Hosoi, "Trends in the incidence of hip fracture in Japan, 1987-1997: the third nationwide survey," Journal of Bone and Mineral Metabolism, vol. 18, no. 3, pp. 126-131, 2000.

[7] J. A. Kanis, O. Johnell, C. de Laet, B. Jonsson, A. Oden, and A. K. Ogelsby, "International variations in hip fracture probabilities: implications for risk assessment," Journal of Bone and Mineral Research, vol. 17, no. 7, pp. 1237-1244, 2002.

[8] H. Orimo, Y. Yaegashi, T. Onoda, Y. Fukushima, T. Hosoi, and K. Sakata, "Hip fracture incidence in Japan: estimates of new patients in 2007 and 20-year trends," Archives of Osteoporosis, vol. 4, no. 1-2, pp. 71-77, 2009.

[9] S. Fujiwara, F. Kasagi, N. Masunari, K. Naito, G. Suzuki, and M. Fukunaga, "Fracture prediction from bone mineral density in Japanese men and women," Journal of Bone and Mineral Research, vol. 18, no. 8, pp. 1547-1553, 2003.

[10] M. Ishikawa, K. Nakamura, T. Tamura, S. Akiyama, and Y. Tsuchiya, "Ethnic differences between Asians and Caucasians in the incidence of osteoporotic fractures: a review," Acta Medica et Biologica, vol. 54, no. 3, pp. 63-66, 2006.

[11] P. D. Ross, S. Fujiwara, C. Huang et al., "Vertebral fracture prevalence in women in Hiroshima compared to Caucasians or Japanese in the US," International Journal of Epidemiology, vol. 24, no. 6, pp. 1171-1177, 1995.

[12] A. M. Briggs, A. M. Greig, and J. D. Wark, "The vertebral fracture cascade in osteoporosis: a review of aetiopathogenesis," Osteoporosis International, vol. 18, no. 5, pp. 575-584, 2007.

[13] S. Nojiri, R. T. Burge, J. A. Flynn, S. A. Foster, and H. Sowa, "Osteoporosis and treatments in Japan: management for preventing subsequent fractures," Journal of Bone and Mineral Metabolism, vol. 31, no. 4, pp. 367-380, 2013.

[14] N. Yoshimura, S. Muraki, H. Oka et al., "Profiles of vitamin D insufficiency and deficiency in Japanese men and women: association with biological, environmental, and nutritional factors and coexisting disorders: the ROAD study," Osteoporosis International, vol. 24, no. 11, pp. 2775-2787, 2013.

[15] S. Fujiwara, T. Nakamura, H. Orimo et al., "Development and application of a Japanese model of the WHO fracture risk assessment tool (FRAX)," Osteoporosis International, vol. 19, no. 4, pp. 429-435, 2008.

[16] N. D. Nguyen, S. A. Frost, J. R. Center, J. A. Eisman, and T. V. Nguyen, "Development of a nomogram for individualizing hip 
fracture risk in men and women," Osteoporosis International, vol. 18, no. 8, pp. 1109-1117, 2007.

[17] K. Åkesson, D. Marsh, P. J. Mitchell et al., "Capture the fracture: a best practice framework and global campaign to break the fragility fracture cycle," Osteoporosis International, vol. 24, no. 8, pp. 2135-2152, 2013.

[18] M. Sakuma, N. Endo, T. Oinuma et al., "Incidence and outcome of osteoporotic fractures in 2004 in Sado City, Niigata Prefecture, Japan," Journal of Bone and Mineral Metabolism, vol. 26, no. 4, pp. 373-378, 2008.

[19] M. Sakuma, N. Endo, T. Oinuma et al., "Incidence of osteoporotic fractures in Sado, Japan in 2010," Journal of Bone and Mineral Metabolism, vol. 32, no. 2, pp. 200-205, 2014.

[20] G. G. Liu, M. D. Dibonaventura, Y. Yuan et al., "The burden of illness for patients with viral hepatitis C: evidence from a national survey in Japan," Value in Health, vol. 15, no. 1, pp. S65S71, 2012.

[21] M. E. Charlson, P. Pompei, K. A. Ales, and C. R. MacKenzie, "A new method of classifying prognostic comorbidity in longitudinal studies: development and validation," Journal of Chronic Diseases, vol. 40, no. 5, pp. 373-383, 1987.

[22] J. Ware, M. Kosinski, D. Turner-Bowker et al., SF-12v2: How to Score Version 2 of the SF-12 Health Survey, Quality Metric Incorporated Health Assessment Lab, Boston, Mass, USA, 2002.

[23] S. Fukuhara and Y. Suzukamo, Manual of SF-36v2 Japanese Version, Institute for Health Outcomes and Process Evaluation Research, Kyoto, Japan, 3rd edition, 2011.

[24] J. E. Brazier and J. Roberts, "The estimation of a preferencebased measure of health from the SF-12," Medical Care, vol. 42, no. 9, pp. 851-859, 2004.

[25] M. C. Reilly, A. S. Zbrozek, and E. M. Dukes, “The validity and reproducibility of a work productivity and activity impairment instrument," PharmacoEconomics, vol. 4, no. 5, pp. 353-365, 1993.

[26] P. Kothawala, E. Badamgarav, S. Ryu, R. M. Miller, and R. J. Halbert, "Systematic review and meta-analysis of real-world adherence to drug therapy for osteoporosis," Mayo Clinic Proceedings, vol. 82, no. 12, pp. 1493-1501, 2007.

[27] M. Kamatari, S. Koto, N. Ozawa et al., "Factors affecting longterm compliance of osteoporotic patients with bisphosphonate treatment and QOL assessment in actual practice: alendronate and risedronate," Journal of Bone and Mineral Metabolism, vol. 25, no. 5, pp. 302-309, 2007.

[28] I. Gorai, Y. Tanaka, S. Hattori, and Y. Iwaoki, "Assessment of adherence to treatment of postmenopausal osteoporosis with raloxifene and/or alfacalcidol in postmenopausal Japanese women," Journal of Bone and Mineral Metabolism, vol. 28, no. 2, pp. 176-184, 2010.

[29] I. Tanaka, M. Sato, T. Sugihara et al., "Adherence and persistence with once-daily teriparatide in Japan: a retrospective, prescription database, cohort study," Journal of Osteoporosis, vol. 2013, Article ID 654218, 8 pages, 2013.

[30] T. J. Jones, R. J. Petrella, and R. Crilly, "Determinants of persistence with weekly bisphosphonates in patients with osteoporosis," Journal of Rheumatology, vol. 35, no. 9, pp. 1865-1873, 2008.

[31] J. Dequeker, J. Aerssens, and F. P. Luyten, "Osteoarthritis and osteoporosis: clinical and research evidence of inverse relationship," Aging Clinical and Experimental Research, vol. 15, no. 5, pp. 426-439, 2003.
[32] C. T. Ng and M. P. Tan, "Osteoarthritis and falls in the older person," Age and Ageing, vol. 42, no. 5, Article ID aft070, pp. 561-566, 2013.

[33] M. E. Maruish, User's Manual for the SF-36v2 Health Survey, Quality Metric Incorporated, Lincoln, RI, USA, 3rd edition, 2011. 


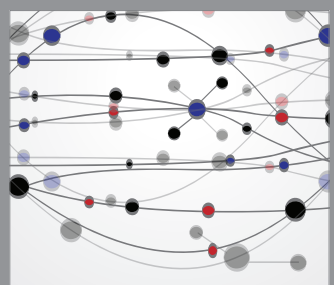

The Scientific World Journal
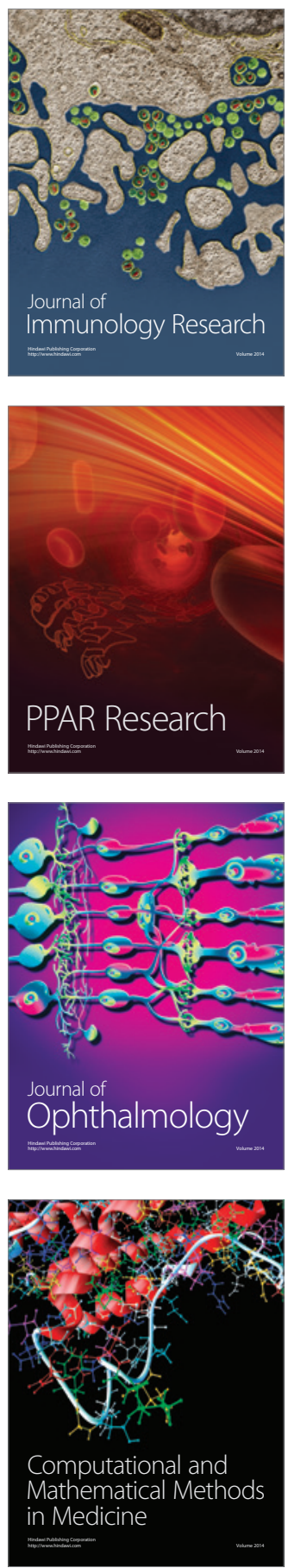

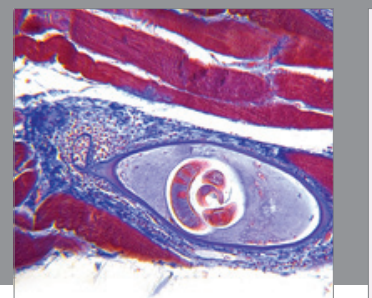

Gastroenterology

Research and Practice
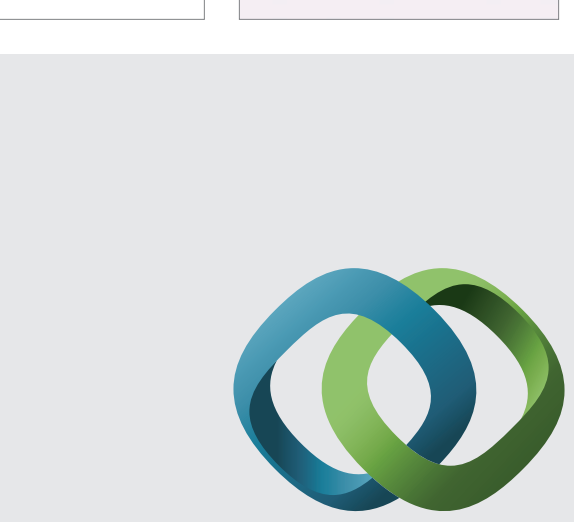

\section{Hindawi}

Submit your manuscripts at

http://www.hindawi.com
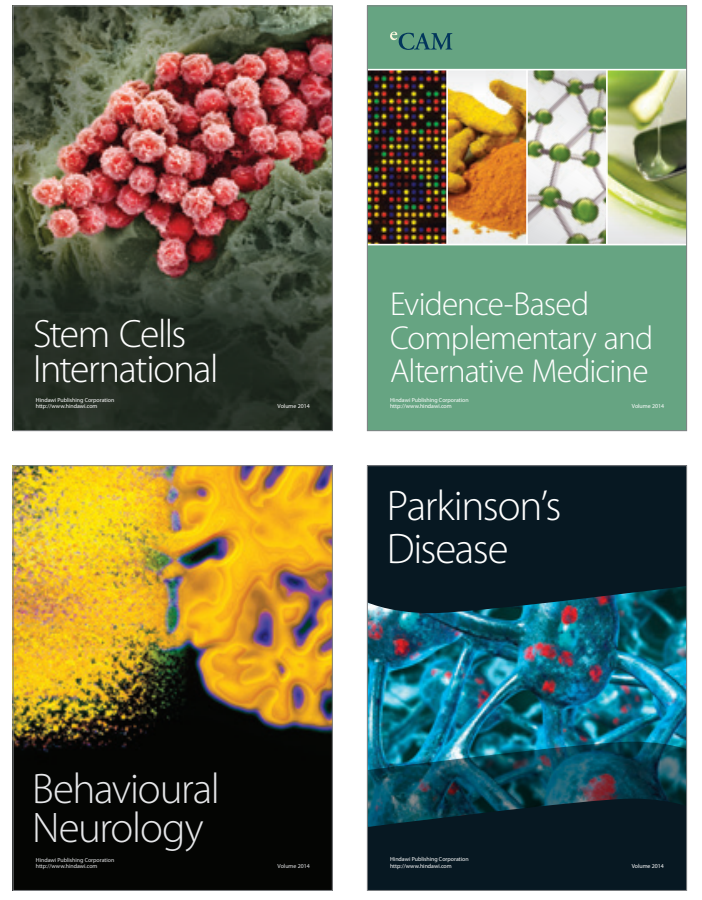
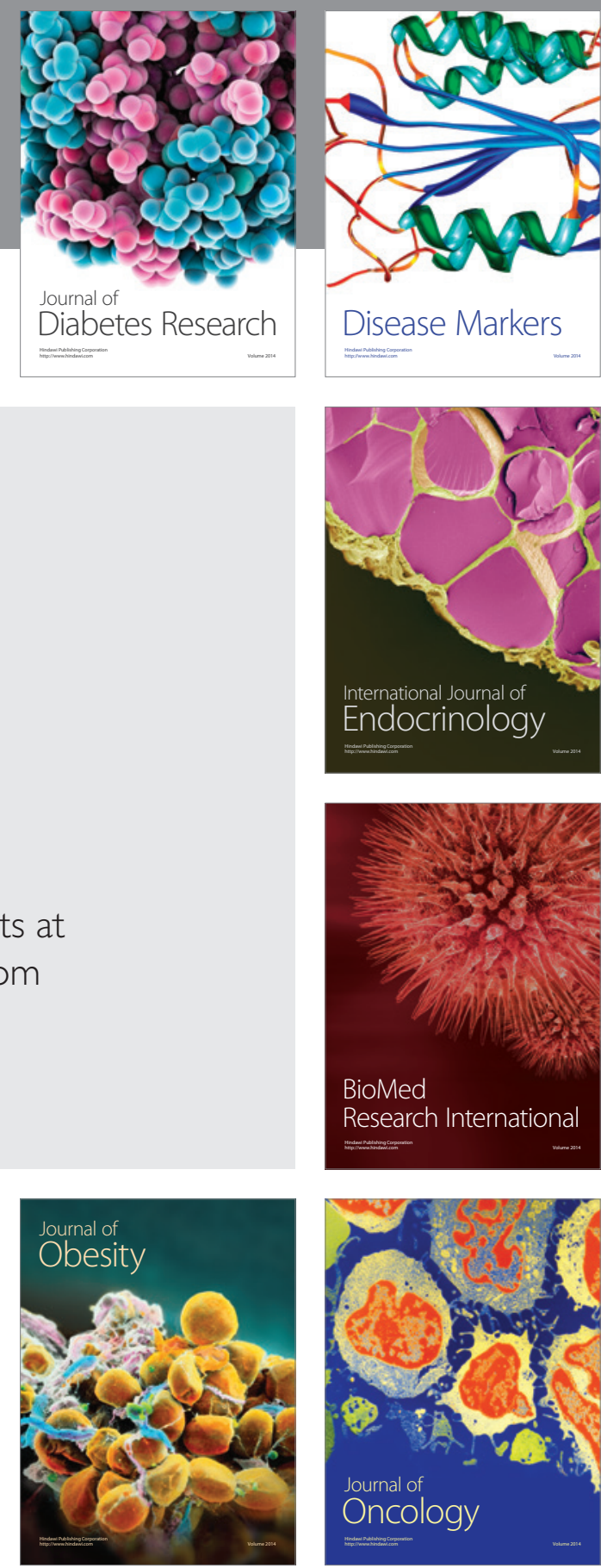

Disease Markers
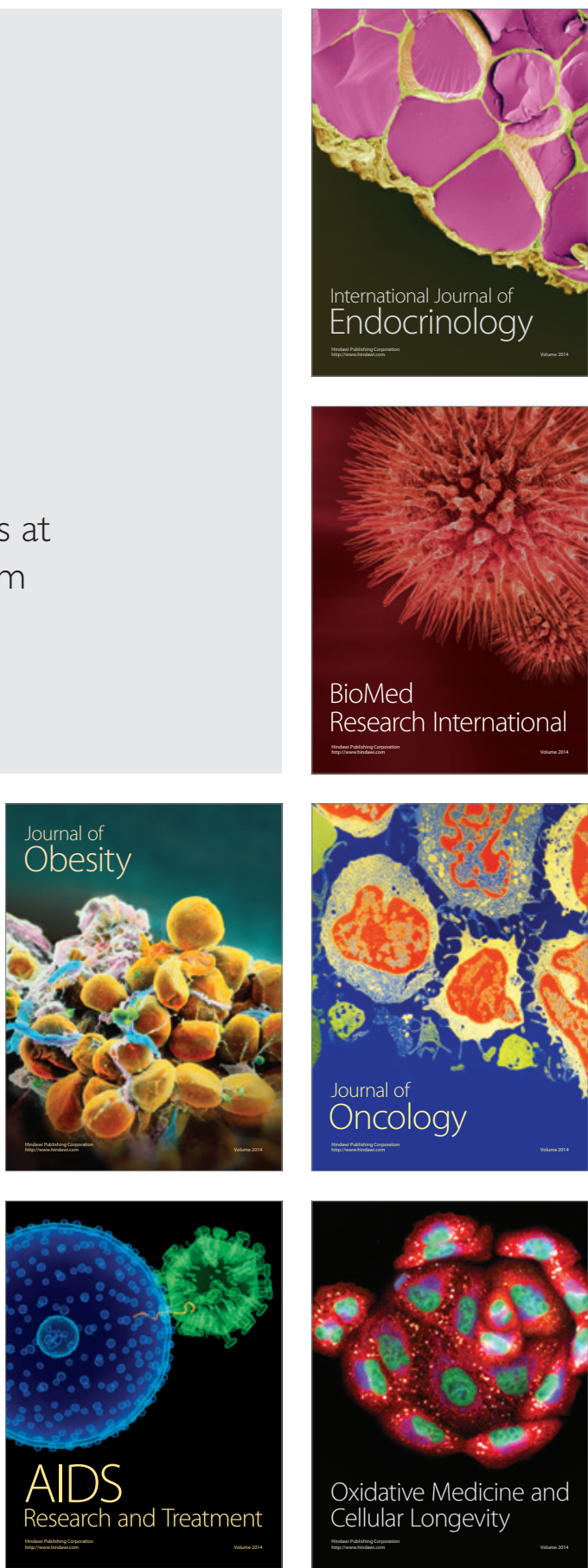